\title{
Severity of Coercive Sexual Harassment in Professor- Student Interaction and Peer Bystander Responses
}

\author{
Donna M. L. Heretick, PhD \\ Walden University, Minneapolis, Minnesota, United States \\ (iD https://orcid.org/0000-0002-2583-3303 \\ Inna V. Learn, MS \\ Walden University, Minneapolis, Minnesota, United States \\ (iD) https://orcid.org/0000-0003-3985-142X
}

Contact: donna.heretick@mail.waldenu.edu

\section{Abstract}

The risk for female students in academia of sexual harassment by male faculty and staff remains a national crisis. This study examined effects of severity of coercive sexual harassment (CSH) by a male professor of a female student on peer bystander intervention responses. A total of 180 undergraduate and graduate college students who volunteered for an online survey were randomly assigned to one of three vignette conditions that varied severity of CSH. Following Bowes-Sperry's ethical model of bystander behaviors, it was predicted that severity of CSH would affect cognitive appraisals and emotional reactions, which would further predict intentions for intervention behaviors. Predictions generally were supported. Logistic regression analyses indicated that severity of $\mathrm{CSH}$, fears of consequences, and negative emotions toward the professor were significant predictors of direct confrontation of the professor by the student observer, whereas only severity and negative emotions toward the professor were predictors of the indirect intervention (finding an excuse to remove the victim) or delegation (going to get help) while the incident was occurring. Fears of personal consequences suppressed direct intervention in the moderate condition. Findings suggest ongoing need within academia for clarification of behaviors that constitute $\mathrm{CSH}$, as well as safety for bystanders who intervene.

Keywords: Sexual harassment; college; faculty-student; bystander response; Bowes-Sperry; vignettes; experiment

Date Submitted: January 31, 2020 | Date Published: May 20, 2020

\section{Recommended Citation}

Heretick, D. M. L., \& Learn, I. V. (2020). Severity of coercive sexual harassment in professor-student interaction and peer bystander responses. Journal of Social, Behavioral, and Health Sciences, 14, 87-105. https://https://doi.org/10.5590/JSBHS.2020.14.1.07 


\section{Introduction}

Bystander intervention is considered an untapped resource to deter sexual harassment (SH; Tenbrunsel et al., 2019). This includes SH in academia, where the risk for female students of unwanted social-sexual behavior remains a national crisis (Cantalupo \& Kidder, 2018): $62 \%$ of female undergraduates and $44 \%$ of female graduate students experience $\mathrm{SH}$, as well as $70 \%$ of females on research field activities (Tenbrunsel et al., 2019) and 55\% on social work field placements (Moylan \& Wood, 2016). Rosenthal and colleagues (2016) reported that $38 \%$ of female and $23.4 \%$ of male graduate students who responded to a survey indicated that they had experienced SH from faculty and staff, and this trend continues, with females more frequently the target by male faculty and staff members (Cantalupo \& Kidder, 2018; Tenbrunsel et al., 2019). Risks and encounters with SH within academia affect female students' psychological and physical well-being, and their educational choices, achievements, and career opportunities (Cortina \& Wasti, 2005; Diekmann et al., 2013; Laird \& Pronin, 2019; National Academies of Sciences, Engineering, \& Medicine, 2018). Female victims also fear that disclosure of the $\mathrm{SH}$ will lead to retaliation from the male faculty or staff perpetrator, as well as negative social perceptions of them by peers (Cantalupo \& Kidder, 2018; Weiss \& Lalonde, 2001).

\section{Types and Severity of Coercive Dyadic SH}

The U.S. Equal Employment Opportunity Commission (n.d.) generally defines SH as follows:

Unwelcome sexual advances, requests for sexual favors, and other verbal or physical conduct of a sexual nature constitute sexual harassment when this conduct explicitly or implicitly affects an individual's employment, unreasonably interferes with an individual's work performance, or creates an intimidating, hostile, or offensive work environment. (para. 2)

In the quid pro quo form of $\mathrm{SH}$, one member of the dyad has higher status over the other member and uses this status to exchange outcomes for sexual favors (National Academies of Sciences, Engineering, and Medicine, 2018). Dyadic quid pro quo SH may involve unwanted sexual attention or sexual coercion (Gelfand et al., 1995). Dyadic sexual coercion specifically includes behaviors that either overtly or implicitly link sexual compliance to job or academic outcomes for the lower status member (Jacobson \& Eaton, 2018; Tata, 2000).

University policies (The State University of New York, 2018) describe coercive SH behaviors as ranging in severity from "seeking sexual favors or a sexual relationship in return for the promise of a favorable grade or academic opportunity" (para. 12), to

Intentional and undesired physical contact, sexually explicit language or writing, lewd pictures or notes, and other forms of sexually offensive conduct by individuals in positions of authority, coworkers or student peers, that unreasonably interferes with the ability of a person to perform their employment or academic responsibilities, (para. 14)

to

Physical acts of a sexual nature, such as: touching, pinching, patting, kissing, hugging, grabbing, brushing against, or poking another person's body; rape, sexual battery, molestation or attempts to commit these assaults. (para. 15)

Many universities list coercive SH with inappropriate touching or physical invasion ("direct contact with an intimate body part"; Worth v. Tyler, 2001) as "sexual contact" (e.g., Swarthmore College, 2019) or "sexual assault" (e.g., Northwestern University, 2018). College student samples have rated sexual coercion as more severe than peer-initiated unwanted sexual attention (Fitzgerald \& Ormerod, 1991; Jacobson \& Eaton, 2018; 
Terpstra \& Baker, 1987), and peer-initiated quid pro quo SH as more severe than hostile work environment (Benavides-Espinoza \& Cunningham, 2010).

To date, no previous studies have focused on comparisons of observers' responses within a subtype of SH (Jacobson \& Eaton, 2017). The current study addressed this gap. The primary research question was whether peer bystander responses would differ in relation to the severity of coercive sexual harassment (CSH). Specifically, students responded to scenarios that presented varying levels of $\mathrm{CSH}$ in dyadic interactions between a person in authority (a male professor) and a subordinate (a female student). The lowest severity condition presented friendly, individual, supportive attention to a student, but without any sexual inferences or actions, the moderate condition presented CSH sexual inferences and some casual physical contact, and the high severity condition presented CSH with sexual inferences and physical violation (invasive sexual groping). In keeping with models of bystander helping behaviors (Bowes-Sperry \& O'Leary-Kelly, 2005; Latané \& Darley, 1970), cognitive appraisals, emotional reactions, and behavioral response intentions were examined. Results indicate clear relationships between severity of CSH and bystander responses.

\section{Bystander Responses}

\section{Cognitive appraisals}

Social cognitive theory posits that individuals process stimuli through proactive cognitive processes of selfreflection, self-regulation, and self-organization, as they integrate personal, environmental, and behavioral factors (Bandura, 1986, 1989). Relatedly, Latané and Darley (1970) and Latané and Nida's (1981) early research supported a stepwise, multifactor model of helping behavior that included a series of initial cognitive appraisals that influenced witnesses' behavioral responses to emergencies. Likelihood of positive bystander intervention increases as the observer (a) perceives an event as requiring a helping intervention, (b) experiences self as responsible for acting, (c) does not perceive or disregards possible personal costs to self of intervening, (d) believes his or her intervention will be effective, and (e) can identify specific ways to help. Indeed, interviews of college students indicated that likelihood of intervention involving sexual assault increased when they believed they should do something, accepted personal responsibility, and decided/intended to help (Bennet et al., 2014).

Bowes-Sperry and Powell (1999) introduced arguments that observers of social-sexual behavior in the workplace also are pressed to make ethical decisions, and that moral reasoning includes cognitive appraisals of harm and culpability. They based their approach on earlier work by Jones (1991) and Rest (1986) on stages of ethical decision making. Probability of perceiving an interaction as SH should increase when the observer perceives "a greater degree of imposition by the initiator on the target" (Bowes-Sperry \& Powell, 1999, p. 782783). The observer would continue to consider motivation of the actor and harm to the victim. Indeed, Chui and Dietz (2014) asked graduate and undergraduate students in Switzerland to read vignettes that described dyadic exchanges that involved uncivil behaviors. When the actor's uncivil behavior was described as arising from a more malicious intent, observers described a higher "necessity to intervene." Further, the greater the perceived harm to the victim ("magnitude of consequences"), the greater the probability of observers' intentions to intervene (Bowes-Sperry \& Powell, 1999, p. 780).

\section{Emotional components}

Behaviors by observers of SH may be guided by their emotional reactivity to perpetration and victimization (O’Leary-Kelly \& Bowes-Sperry, 2001). Wiener and Hurt (2000) proposed a causal cognition-emotionbehavior sequence for how people evaluate sociosexual behaviors in the workplace: Once judgments of responsibility for harm are made, emotional reactions follow, and these emotional reactions influence the observer's reaction, such as help-giving or aggression. For example, the less the perceived responsibility of the victim for the wrong, the more positive the emotional reaction toward the victim, and the higher the likelihood of a helping intervention. 
With respect to bullying, among adolescents, emotional responses (e.g., feeling sorry for the victim) and attitudes toward bullying (i.e., beliefs about correct normative behaviors) were found to be most strongly correlated with interpreting an event as an emergency (e.g., "someone who is being bullied needs help"), accepting responsibility ("I feel personally responsible to intervene...."), and implementing an intervention (e.g., "I would say something to the student who is acting mean...."; Nickerson et al., 2014). In keeping with the assumptions that empathy has two dimensions, cognitive (perspective taking) and affective (emotion sharing; Batson, 1991; Davis, 1996), Barlinska and colleagues (2018) observed that adolescents were much more likely to offer active support to a victim of cyberbullying when they moved beyond perspective taking to actual emotional concern, such as worry, for the victim.

In his work on moral foundations, Haidt (2003) initially proposed anger as an emotional response specific to violations of personal rights and disgust as a reaction specific to impure behaviors, such as taboo sexual acts. However, anger and disgust appear to be emotional reactions to perpetrators of both types of violations (Cameron et al., 2015; Gibbs, 2019; Giner-Sorolla \& Chapman, 2017). Further, Halmburger and colleagues (2015) identified anger as a component of moral courage: Using an experimental design, bystander's selfreported anger toward a perpetrator's behavior (theft of someone else's property) was a strong predictor of actual intervention behavior.

\section{Intervention behaviors}

Bowes-Sperry and O'Leary-Kelly (2005) proposed that observer intervention for SH is more likely when there is low ambiguity in the situation and the harm caused to the victim is imminent. Indeed, there is empirical support that higher risk behavioral intervention is more likely when there is less ambiguity about the occurrence and higher severity of the offense (Jacobson \& Eaton, 2018). Bowes-Sperry and O'Leary-Kelly (2005) also proposed that directness of a bystander's behavioral response varies. For example, during the incident, the observer could step in and directly confront the perpetrator, openly identifying the wrongdoing, or could choose a more indirect type of involvement, such as making up an excuse to help remove the victim from the situation without confronting the harasser or publicly identifying the wrong. College trainings in bystander intervention to $\mathrm{SH} /$ violence present a third type of response, delegate (Coker et al., 2015). The third option is another example of indirect help at the time of the incident. Here, the observer looks for help from others to intervene. Acting after the incident is over could involve choices such as offering to accompany the target to file a complaint against the perpetrator (direct involvement) or privately offering comfort to the target (indirect involvement).

\section{Research Questions}

The focus of this study was to address peer bystander responses to situations of CSH in the academic setting where the perpetrator is a male college professor and the victim is a female student. The decision to use this specific dyad was based on reports that female students who experience SH are more frequently the target of male faculty and staff members (Cantalupo \& Kidder, 2018; Tenbrunsel et al., 2019). Applying the models of helping behavior that have been reviewed, there were three primary research questions for this study.

Research Question 1: Does severity of quid pro quo CSH behaviors in a professor-student interaction affect peer observers' cognitive appraisals and emotional reactions?

We proposed that cognitive appraisals related to perceived harm to the victim, personal responsibility to act, fears of negative consequences, as well as negative emotional responses toward the perpetrator and positive toward the victim, would increase across the three vignette groups as the severity of the professor's offense increased.

Research Question 2: Does severity of quid pro quo CSH behaviors in a professor-student interaction affect peer observers' behavioral intentions for three types of bystander responses? 
First, we proposed that observers' overall intentions to engage in some form of intervention would increase across the three vignette groups as the severity of the professor's offense increased. Second, of the three types of interventions considered by the observers, the most direct response, willingness to confront the professor directly during the incident, would be the one that would be markedly more acceptable among those in the condition with physical violation (CSH-PV) as compared with those in the moderate, potentially more ambiguous, or low severity conditions.

Research Question 3: The final focus was to evaluate via regression analysis the relative contribution of the severity of the quid pro quo coercive $\mathrm{SH}$, as well as the cognitive appraisals and emotional responses, in predicting observers' intentions for each type of intervention behavior.

\section{Methods}

This study employed an experimental design with systematic manipulation of the severity of coercive quid pro quo SH. Dependent variables included cognitive appraisals, emotional reactions, and behavioral intentions regarding bystander intervention.

\section{Independent Variable: Vignettes to Manipulate Severity of CSH}

In the tradition of using vignettes to study bystander intervention related to SH among students (e.g., Bennett et al., 2015; Bursik \& Gefter, 2011; Jacobson \& Eaton, 2018; Weiss \& Lalonde, 2001), three vignettes were created to present descriptions of interactions between a male professor and a female college student that varied in severity of CSH.

All vignettes began with a description of an encounter that the participant reader is said to witness in which the professor approaches the student at the end of a class meeting and invites her to come by his office the next day to discuss her paper. The reader was then told, "The next day, you are working in a room that adjoins the professor's office. You are alone and able to see and hear what goes on in the office without anyone else's awareness that you are there."

Depending on the experimental condition, readers then read one of three descriptions of the office encounter: one that depicted appropriate behavior, one that depicted coercive SH (CSH), and one with coercive SH with intrusive physical violation (CSH-PV). In the appropriate condition, the professor was described as formal, but friendly and commenting on the quality of the student's work and his desire to work with her. In the two descriptions of coercive sexual misconduct, the professor was described as both informal and friendly, commenting on the student's physical attractiveness and suggesting that she needs to "loosen up." In the CSH condition, participants read,

While talking with Karen, Professor Brooks moves closer, and touches her knee and her shoulder. Professor Brooks then says, putting his hand on her knee and making direct eye contact, that he looks forward to more of their individual meetings: "You decorate my office just sitting there!" He asks if they might meet for dinner later in the week, and adds, "That's one sure way not to fail my course."

In the CSH-PV scenario, the description was,

While talking with Karen, Professor Brooks moves closer and puts his arm around her. As she nervously tries to move away, he pulls her closer, fondling her breast. He then takes her hand and moves it to rest on his groin. Making direct eye contact, he softly says that he looks forward to more of their individual meetings: "You decorate my office just sitting here!" He asks if they might meet for dinner later in the week, and adds, "That's one sure way not to fail my course." 


\section{Instrumentation: Dependent Variables}

\section{Characteristics of the interactions}

The first five items in the survey after the introduction of the vignette were intended as a manipulation check as they evaluated characteristics that we assumed varied systematically across the three experimental scenarios. These dimensions were selected because they were compatible with those considered in college and university policies regarding professional conduct, legal definitions of sexual misconduct, sexual behaviors, $\mathrm{SH}$, sexual assault, sexual coercion, and sexual hostility.

Items began with the following question: "In your opinion, how would you characterize the interaction between Professor Brooks and Karen in this story for each of the following items?" We provided no definitions for the terms. End-point and midpoint descriptors of the even-numbered 8-point scale labeled conceptual variations from low-risk to high-risk forms of that particular behavioral element (Chyung et al., 2017). (Items are shown in Table 1.)

\section{Perceived harm to victim}

One item was constructed to evaluate the perceived level of harm to the student. Following recommendations by Schein and Gray (2018) for operationally defining harm along a continuum, we again presented an 8-point scale with anchors ranging from 1 (no harm) to 4-5 (moderate harm) to 8 (extreme harm).

\section{Cognitive appraisals}

Each of the following items for all subscales included a 7-point Likert-type scale, 1 (strongly disagree) to 7 (strongly agree). The 7-point scale replicated procedures for items adapted from Chui and Dietz (2014), and then was consistent across other subscales that followed.

\section{Personal responsibility to act}

We replicated three items previously developed by Chui and Dietz (2014) to apply the Bowes-Sperry model to bystander responses to workplace incivility. Although Chui and Dietz labeled the items "necessity to intervene," we conceptualize them as varying in responsibility to act. The items were "I feel compelled to do something about the situation," "I feel something should be done about this situation," "I feel I should mind my own business and not get involved." We believe that the first item indicates a sense of personal responsibility, the second connotes general responsibility, and the third expresses no responsibility to act. Chui and Dietz (2014) reported internal consistency of the three items at $\alpha=.72$. Similar to Chui and Dietz, we reverse scored the third item and computed the unweighted average of the ratings to create a single index of sense of personal responsibility for the logistic regression analysis.

\section{Fears of negative consequences}

Two items were taken from previous work by Hellemans, Dal Cason, and Casini (2017) to assess two types of fears of negative consequences of intervening among peer bystanders of bullying in the workplace. The first item evaluated fear of personal cost: I would be afraid to intervene in the situation for fear of negative consequences for me as a student. The next statement evaluated fears regarding intervention self-efficacy: $I$ would be afraid to intervene in the situation for fear of making the situation worse.

\section{Emotional Responses to Perpetrator and Victim}

We evaluated four emotional responses to both the professor and the student: anger, worry, disgust, and sadness. All eight items began with, "While the incident between Professor Brooks and Karen is occurring, I..." The same item was presented twice, once referring to the professor and once referring to the student. For example, a pair of separate items was, "I would be angry at Professor Brooks for his actions" and then "I would be angry at Karen for her actions." 


\section{Behavioral Intentions}

Because actual live situations of CSH were not presented to participants, in which their actual responses could be observed, we relied on assessment of behavioral intention. This approach is supported by previous research into helping behaviors (e.g., Bennett et al., 2015; Hellemans et al., 2017). Following examples provided by Bowes-Sperry and O’Leary-Kelly (2005) and college bystander intervention trainings (e.g., Coker et al., 2015), three items described possible intervention behaviors while the incident was occurring. These were "interrupt the interaction and make up an excuse to get Karen out of there" (distract), "go in and tell Professor Brooks to his face to stop what he is doing with Karen" (direct), and "go find someone to help me go in and stop what is going on" (delegate).

\section{Sampling and Procedures}

This study was approved by our university's Institutional Review Board. A target goal of 180 adults, 18 or older, who currently were undergraduate or graduate students at on-campus programs of college or universities in the United States or Canada, and fluent in English were recruited through Prolific Academic to participate in an online survey concerning "How do students respond after observing a faculty-student interaction?” Prolific Academic is a reliable online crowdsourcing service that identifies individuals who volunteer to participate, for compensation, in online surveys for scientific research (Peer et al., 2017). Completers were compensated $\$ 1.63$ for their time (following guidelines from Prolific). Completion took less than 15 minutes. Recruitment ended when we met the goal of 180 completed surveys. A total of 188 members responded and, of these, 180 provided consent and moved on to complete the full survey. Those who consented proceeded to the demographic questionnaire and then to the survey (freeonlinesurveys.com). We randomly assigned participants to one of three vignette conditions. The vignette was presented at the beginning of the first page of the survey and was repeated at the beginning of each new page so that it always was available for review during all parts of the survey. Data were downloaded from the survey site in spreadsheet form, and then were transferred to SPSS (Version 26) datafiles for analyses.

\section{Characteristics of the Participants}

Our sample had fairly even representation on gender (female $=52.8 \%$ ). The majority were Caucasian $(58.9 \%$ ), followed by Asian/Pacific Islanders (12.8\%), and six other groups, each with less than $9 \%$ representation. The majority (84.4\%) attended college in the United States and the remainder in Canada, were undergraduates (77.2\%), studying full-time (79.4\%), and studying on campus (58.3\%) or a mixture of on-campus and online (32.2\%). Chi-Square analyses of each of the categorical demographic variables indicated that the distribution of demographic characteristics of participants in the three vignette groups did not deviate from chance. The mean age of the undergraduate and graduate participants also did not vary significantly across experimental conditions: mean age for Condition A, 23.63 years (4.62; $N=63)$; Condition $\mathrm{B}, 24.39(5.69 ; N=56)$; Condition C, $23.21(5.09 ; N=61), F(2,177)=.79, p=.456$.

\section{Results}

\section{Manipulation Check}

Results confirm that the three vignettes presented significantly different levels of severity of CSH. Table 1 presents the group size, mean, standard deviation for each of the five items, and the overall mean rating scores for perceptions of the severity of social-sexual behaviors presented across the three vignette conditions. Because item response scales were ordinal and distributions of ratings did not meet assumptions for normality or homogeneity of variances, Kruskal-Wallis $H$ tests were used to examine differences between vignette groups (see Table 1 for details of analyses). As predicted, there were statistically significant overall 
between-group differences for each of the items $(p<.001)$. Also, post hoc tests (Bonferroni correction) indicated that Group A (low CSH) was significantly lower on severity than Group B (moderate CSH) and Group C (high, CSH-PV) for all items ( $p<$.oo1). Ratings by Group C were significantly higher than those for Group B characterization of the interaction as sexual ( $p=.002)$, sexual assault ( $p=.004)$, and sexual hostility $(p=.024)$. While Groups B and C did not differ significantly for sexual coercion, the difference trended in the predicted direction $(p=.077)$. The internal consistency across the five items was $\alpha=.969$. As would be expected based on individual items, between-group differences for the overall mean rating for the five items also were statistically significant, $\chi^{2}(2)=128.22, p<.001$. All post hoc pairwise comparisons (Bonferroni) of the overall means were statistically significant: $\mathrm{A}-\mathrm{B}, p<.001 ; \mathrm{A}-\mathrm{C}, p<.001 ; \mathrm{B}-\mathrm{C}, p=.003$.

Table 1. Mean Ratings for Observers' Perceptions of Severity of Sexually Coercive Behaviors Described in Vignette

\begin{tabular}{|c|c|c|c|c|c|}
\hline \multirow[b]{2}{*}{$\begin{array}{l}\text { Kruskal-Wallis } H \text { test } \\
\quad(\text { scale }=1-7)\end{array}$} & \multicolumn{3}{|c|}{ Vignette condition } & \multirow[b]{2}{*}{$\chi^{2}$} & \multirow[b]{2}{*}{$\boldsymbol{p}$} \\
\hline & Low CSH & $\begin{array}{l}\text { Moderate } \\
\quad \text { CSH }\end{array}$ & High CSH & & \\
\hline $\begin{array}{l}\text { Very professional to very } \\
\text { unprofessional }\end{array}$ & $2.45(1.50)$ & $7.61(1.20)$ & $7.92(.52)$ & 146.59 & $<.001$ \\
\hline Absolutely nonsexual to very sexual & $2.05(1.57)$ & $6.54(1.51)$ & $7.55(1.04)$ & 121.61 & $<.001$ \\
\hline Appropriate to SH to sexual assault & $1.69(1.20)$ & $5.64(1.42)$ & $6.90(1.26)$ & 122.94 & $<.001$ \\
\hline $\begin{array}{l}\text { No sexual coercion to extreme sexual } \\
\text { coercion }\end{array}$ & $1.71(1.37)$ & $6.02(1.48)$ & $6.82(1.44)$ & 115.26 & $<.001$ \\
\hline $\begin{array}{l}\text { No sexual hostility to extreme sexual } \\
\text { hostility }\end{array}$ & $1.58(1.03)$ & $5.30(1.82)$ & $6.44(1.39)$ & 113.78 & $<.001$ \\
\hline Overall mean score for five items & $1.90(1.11)$ & $6.22(1.09)$ & $7.13(.85)$ & 128.22 & $<.001$ \\
\hline
\end{tabular}

Note. $\mathrm{CSH}=$ coercive sexual harassment. Group sizes were as follows: Group A, 62; Group B, 56; Group C, 62.

\section{Research Hypotheses}

Hypothesis 1. Social-cognitive appraisals and emotional responses: Observers' ratings on perceived harm to the victim, personal responsibility to act, fears of negative consequences, and negative emotional responses toward the perpetrator, but positive toward the victim, would increase across the three vignette groups as the severity of the professor's offense increased.

Table 2 summarizes mean ratings and standard deviations for all items used to evaluate between-group differences in cognitive appraisals and emotional responses for observers in the three vignette conditions that varied in the severity of coercive sexual behavior. Again, nonparametric Kruskal-Wallis $H$ tests were used to evaluate between-group differences in mean ranks. Because of the number of statistical tests performed to test between-group differences, alpha for rejection of the null hypothesis was corrected to $p \leq .024$ (Bonferroni correction, .05/21). Bonferroni corrections also were applied for post hoc pairwise comparisons. There were statistically significant overall between-group differences for all variables. Results for each variable follow. 
Table 2. Between-Group Differences in Observers'Perceptions and Behavioral Intent in Relation to Severity of Coercive Sexual Harassment (CSH)

\begin{tabular}{|c|c|c|c|c|c|}
\hline \multirow[b]{2}{*}{ Item/scale score } & \multicolumn{3}{|c|}{ Vignette condition } & \multicolumn{2}{|c|}{ Kruskal-Wallis $H$ test } \\
\hline & Low CHS & Mod CHS & High CSH & $\chi^{2}$ & $\boldsymbol{p}$ \\
\hline Harm to Karen & $1.56(.93)^{\mathrm{b}, \mathrm{c}}$ & $5.30(1.78)^{\mathrm{a}, \mathrm{c}}$ & $6.58(1.14)^{\mathrm{a}, \mathrm{b}}$ & 121.37 & $<.001$ \\
\hline \multicolumn{6}{|l|}{ Personal responsibility } \\
\hline Compelled to do something & $1.89(1.59)^{\mathrm{b}, \mathrm{c}}$ & $5.35(1.49)^{\mathrm{a}, \mathrm{c}}$ & $6.30(.97)^{\mathrm{a}, \mathrm{b}}$ & 106.07 & $<.001$ \\
\hline Something should be done & $1.79(1.34)^{\mathrm{b}, \mathrm{c}}$ & $6.48(1.03)^{\mathrm{a}}$ & $6.73(.68)^{\mathrm{a}}$ & 132.74 & $<.001$ \\
\hline $\begin{array}{l}\text { Should mind my own } \\
\text { business }\end{array}$ & $5.49(1.95)^{\mathrm{b}, \mathrm{c}}$ & $2.68(1.44)^{\mathrm{a}, \mathrm{c}}$ & $1.90(1.24)^{\mathrm{a}, \mathrm{b}}$ & 79.65 & $<.001$ \\
\hline $\begin{array}{l}\text { Personal responsibility } \\
\text { score ( } 3 \text { items) }\end{array}$ & $2.06(1.34)^{\mathrm{b}, \mathrm{c}}$ & $5.72(1.09)^{\mathrm{a}, \mathrm{c}}$ & $6.38(.87)^{\mathrm{a}, \mathrm{b}}$ & 119.62 & $<.001$ \\
\hline \multicolumn{6}{|l|}{ Fear of consequences } \\
\hline $\begin{array}{l}\text { Afraid of personal } \\
\text { consequences }\end{array}$ & $2.79(1.98)^{\mathrm{b}, \mathrm{c}}$ & $4.55(1.77)^{\mathrm{a}, \mathrm{c}}$ & $3.63(1.88)^{\mathrm{a}, \mathrm{b}}$ & 24.07 & $<.001$ \\
\hline $\begin{array}{l}\text { Afraid of making situation } \\
\text { worse }\end{array}$ & $2.56(1.84)^{b}$ & $3.79(1.89)^{\mathrm{a}, \mathrm{c}}$ & $3.27(1.82)^{b}$ & 13.62 & .001 \\
\hline $\begin{array}{l}\text { Negative consequences } \\
\text { score ( } 2 \text { items) }\end{array}$ & $2.68(1.78)^{\mathrm{b}, \mathrm{c}}$ & $4.17(1.58)^{\mathrm{a}}$ & $3.45(1.63)^{\mathrm{a}}$ & 21.86 & $<.001$ \\
\hline \multicolumn{6}{|l|}{ Emotional responses } \\
\hline Angry with professor & $2.03(1.60)^{b, c}$ & $6.52(.74)^{\mathrm{a}}$ & $6.68(.94)^{\mathrm{a}}$ & 127.17 & $<.001$ \\
\hline Angry with Karen & $1.48(1.08)$ & $1.36(.72)$ & $1.24(.82)$ & 3.72 & n.s \\
\hline Worried for professor & $1.74(1.27$ & $1.43(.93)$ & $1.31(.92)$ & 7.28 & n.s \\
\hline Worried for Karen & $2.23(1.73)^{\mathrm{b}, \mathrm{c}}$ & $6.45(.93)^{\mathrm{a}}$ & $6.76(.93)^{\mathrm{a}}$ & 127.16 & $<.001$ \\
\hline Disgusted with professor & $1.90(1.57)^{\mathrm{b}, \mathrm{c}}$ & $6.32(1.24)^{\mathrm{a}}$ & $6.81(.62)^{\mathrm{a}}$ & 132.73 & $<.001$ \\
\hline Disgusted with Karen & $1.37(1.09)$ & $1.18(.43)$ & $1.11(.55)$ & 3.73 & n.s. \\
\hline Feel very sad for professor & $1.40(1.11$ & $1.64(1.27)$ & $1.47(1.13)$ & 3.43 & n.s. \\
\hline Feel very sad for Karen & $1.73(1.44)^{\mathrm{b}, \mathrm{c}}$ & $6.13(1.10)^{\mathrm{a}}$ & $6.50(.88)^{\mathrm{a}}$ & 121.23 & $<.001$ \\
\hline $\begin{array}{l}\text { Anger-disgust for professor } \\
(2 \text { items })\end{array}$ & $1.97(1.56)^{\mathrm{b}, \mathrm{c}}$ & $6.42(.90)^{\mathrm{a}}$ & $6.74(.67)^{\mathrm{a}}$ & 129.09 & $<.001$ \\
\hline $\begin{array}{l}\text { Worry-sadness for Karen ( } 2 \\
\text { items) }\end{array}$ & $1.98(1.51)^{b, c}$ & $6.29(.90)^{\mathrm{a}}$ & $6.63(.66)^{\mathrm{a}}$ & 122.64 & $<.001$ \\
\hline \multicolumn{6}{|l|}{ Behavioral intentions } \\
\hline $\begin{array}{l}\text { Would make excuse to get } \\
\text { Karen out }\end{array}$ & $1.68(1.35)^{b, c}$ & $5.45(1.56)^{\mathrm{a}}$ & $5.89(1.04)^{\mathrm{a}}$ & 106.73 & $<.001$ \\
\hline Would tell professor to stop & $1.55(1.20)^{\mathrm{b}, \mathrm{c}}$ & $3.59(1.93)^{\mathrm{a}, \mathrm{c}}$ & $4.86(1.78)^{a, b}$ & 84.04 & $<.001$ \\
\hline Would go find help & $1.58(1.35)^{b, c}$ & $4.84(1.82)^{\mathrm{a}}$ & $5.50(1.64)^{\mathrm{a}}$ & 94.54 & $<.001$ \\
\hline
\end{tabular}

Note. Group sizes were Group A, 62; Group B, 56; Group C, 62. Superscripts following parentheses in each vignette condition indicate vignette conditions with which group's mean rank differed significantly in pairwise comparisons following Kruskal-Wallis $H$ test. 


\section{Perceived harm to Karen}

Observers' perceptions of harm to Karen directly increased in relation to the severity of the coercive sexual behaviors described in the vignette, $\chi^{2}(2)=121.37, p<.001$. Each group's ratings were significantly different from those of the other two conditions. Also, the scale appeared to be sensitive enough not to have a ceiling effect: The mean rating for the sexual assault group was 6.58 on a scale of 1 to 8 (see Table 2).

\section{Personal responsibility to act}

As predicted, personal responsibility to act, "I feel compelled to do something," $\chi^{2}(2)=106.07, p<.001$, and a sense that "something should be done," $\chi^{2}(2)=132.74, p<.001$, progressively increased with severity of the coercive sexual behavior, with the reverse observed for the option of no responsibility, "mind my own business," $\chi^{2}(2)=79.65 ; p<$.001. All pairwise comparisons of group ratings differed significantly as well.

Following procedures from Chui and Deitz (2014), a single index score also was computed for the variable. The internal consistency of the three items was $\alpha=.93$ and the overall scale mean was $4.69(S D=2.22)$; both of these values were higher than the reliability $(\alpha=.72)$ and the mean $(4.27, S D=1.29), t(346)=2.24, p=$ .033, reported by Chui and Deitz. In our study, the scale scores reflected the predicted pattern: Personal responsibility increased with severity of coercive sexual behavior, $\chi^{2}(2)=119.62, p<.001$, and all pairwise comparisons were statistically significant. See Table 2.

\section{Fear of negative consequences}

There were overall statistically significant between-group differences for both items to evaluate fears of negative outcomes: personal consequences, $\chi^{2}(2)=24.07, p<.001$; making situation worse, $\chi^{2}(2)=13.62, p<$ .001. However, rather than a linear relationship that followed the increasing severity of the CSH, the highest scores for fears of negative consequences occurred in the CSH group, rather than the CSH-PV group. The same pattern resulted when we analyzed the composite score for the two items $(\alpha=.79), \chi^{2}(2)=21.86, p<$ .001). See Table 2.

A related samples Wilcoxon signed-ranks test was used to compare ratings on the two questions within each vignette condition: responses by the same individuals on the two items did not differ in the low CSH condition $(p=.20)$ nor in the CSH-PV condition $(p=.12)$. However, in the CSH condition, the median ranks of ratings for fear of personal consequences were statistically significantly higher than median ranks for fear of making the situation worse if the observer intervened $(Z=-3.17, N=56, p=.002)$. As will be discussed later, this may be related to greater ambiguity regarding the offense in this severity condition, as compared with that where there was physical groping.

\section{Emotional responses}

The first outcome of note is verification that, as expected, emotional responses were different and specific to the perpetrator and to the victim where coercive sexual behavior occurred in the vignette. Ratings for items on anger and disgust toward the professor, and ratings for worry and sadness toward for student, always were higher for the two conditions where CSH was present, when compared with the no-CSH condition $(p<.001)$. See Table 2 for specific outcomes.

The internal consistencies (Cronbach alphas) among subsets of items were as follows: anger and disgust toward professor, $\alpha=.972$; anger and disgust toward student, $\alpha=.772$; worry and sadness toward professor, $\alpha=.634$; worry and sadness toward student, $\alpha=.964(N=180)$. As may be seen in Table 2, again, there were overall statistically significant differences across the three condition groups for composite scores for angerdisgust toward professor, $\chi^{2}(2)=129.09, p<.001$, and for worry-sadness for Karen, $\chi^{2}(2)=122.64, p<.001$. Further, in each case, while both of the higher CSH behavior groups had ratings significantly higher than the ratings for the low $\mathrm{CSH}$ group, and ratings for the $\mathrm{CSH}-\mathrm{PV}$ group were higher, the two CSH-present groups did not differ statistically significantly from each other. 
Hypothesis 2. Intended intervention behaviors during incident: We predicted that behavioral intentions for intervention responses (confront the professor directly, interrupt and find an excuse for the student to leave, go find help) would increase with the severity of the CSH across the three vignette conditions. Willingness to confront the professor directly would be markedly more acceptable among those in the CSH-PV condition as compared with those in the moderate severity CSH condition.

As before, nonparametric Kruskal-Wallis tests were needed to test for between-group differences in ratings on items for each of the three intervention responses (see Table 2). There were overall statistically significant differences for ratings across the three experimental groups $(p<.001)$ for all three intervention options: make excuse to remove Karen, $\chi^{2}(2)=106.73, p<.001$; confront professor, $\chi^{2}(2)=84.04, p<.001$; go for help, $\chi^{2}(2)=94.54, p<.001$. Figure 1 presents the mean ratings for each of the three intervention behaviors for observers in each vignette group. While directly confronting the professor was less popular than the other two options, those in the CSH-PV condition expressed significantly higher agreement with the option to confront than those in the CSH condition.

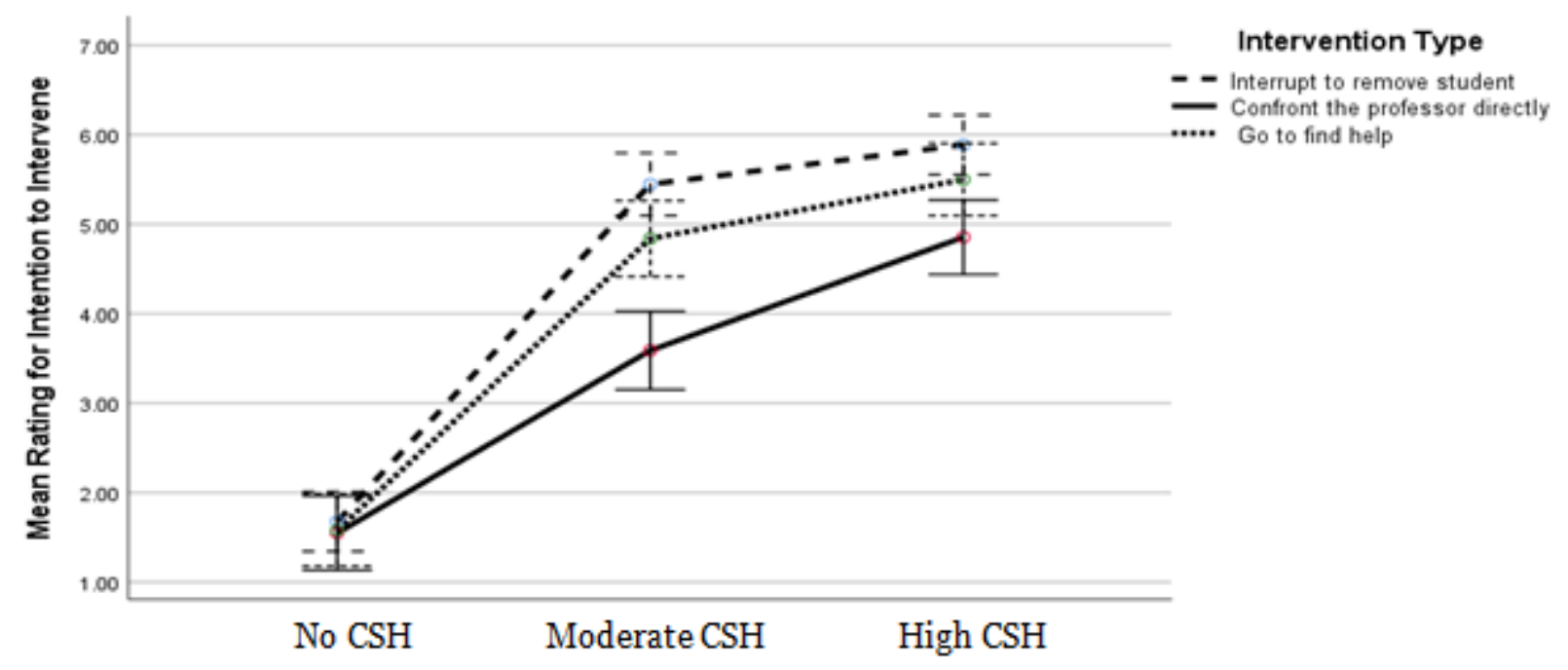

Figure 1. Behavioral Intention for Each Type of Intervention Behavior for Observers in Each of the Three Coercive Sexual Harassment (CSH) Conditions (error bars show 95\% Confidence Intervals)

\section{Test of the Prediction Model for Bystander Intervention Behaviors}

The final goal of this study was to evaluate situational (severity), cognitive appraisal (perceived harm, responsibility to intervene, fear of consequences), and emotional (toward perpetrator and toward victim) factors as predictors of intention to engage in three possible intervention behaviors. First, we computed bivariate Spearman correlations for ratings on all pairs of predictors (see Table 3). With the exception of costbenefit appraisals (fear of consequences), cognitive appraisals, emotional reactions, and behavioral intention for intervention were positively and significantly related.

Again, because scores generally did not meet assumptions to be treated as continuous, all predictor and outcome variables were converted to binary categorical variables (low, high), using median splits. Separate 
binary logistic regressions were performed to evaluate prediction models for each of the three intervention behaviors. See Table 3.

Table 3. Bivariate Relationships Among Cognitive Appraisals, Emotional Responses, and Intervention Behavioral Intentions for Participants in the Three Coercive Sexual Harassment Conditions

\begin{tabular}{|c|c|c|c|c|c|c|c|}
\hline $\begin{array}{l}\text { Appraisals and } \\
\text { intervention options }\end{array}$ & $\mathbf{1}$ & 2 & 3 & 4 & 5 & 6 & 7 \\
\hline 1. Harm to Karen & 1.000 & & & & & & \\
\hline 2. Responsibility to intervene & $.811^{* *}$ & 1.000 & & & & & \\
\hline $\begin{array}{l}\text { 3. Fear of consequences of } \\
\text { intervention }\end{array}$ & $.250^{*}$ & .096 & 1.000 & & & & \\
\hline $\begin{array}{l}\text { 4. Anger-disgust toward } \\
\text { professor }\end{array}$ & $.727^{* *}$ & $.717^{* * *}$ & $.328^{* *}$ & 1.000 & & & \\
\hline 5. Sadness-worry toward Karen & $.823^{* * *}$ & $.837^{* * *}$ & $.266^{* *}$ & $.710^{* *}$ & 1.000 & & \\
\hline $\begin{array}{l}\text { 6. Interrupt, make up excuse to } \\
\text { remove Karen }\end{array}$ & $.719^{* *}$ & $.786^{* *}$ & .088 & $.731^{* *}$ & $.771^{* *}$ & 1.000 & \\
\hline $\begin{array}{l}\text { 7. Confront professor face to face } \\
\text { to stop }\end{array}$ & $.624^{* *}$ & $.725^{* *}$ & -.008 & $.693^{* *}$ & $.651^{* *}$ & $.806^{* *}$ & 1.000 \\
\hline $\begin{array}{l}\text { 8. Go to get help to stop what is } \\
\text { going on }\end{array}$ & $.673^{* *}$ & $.684^{* *}$ & $.250^{* *}$ & $.694^{* *}$ & $.746^{* *}$ & $.678^{* *}$ & $.650^{* *}$ \\
\hline
\end{tabular}

Note. Spearman rho correlations. $N=180$.

${ }^{*} p=.001 .{ }^{* *} p<.001$.

As may be seen in Table 4, severity of the offense toward the student generally was a significant predictor of intentions for all three types of bystander interventions: Interrupt to remove Karen, $\mathrm{CSH}$ and CSH-PV, $p<$ .001; Confront professor, CSH, $p=.015$, CSH-PV, n.s.; Find help, CSH, $p=.002$, CSH-PV, $p=.036$. Also, negative emotions toward the professor significantly predicted or showed a strong trend as a predictor of all three intervention behaviors: interrupt, $p=.09$; confront, $p=.001$; go find help, $p=.021$. Fears of consequences to the bystander only were salient with respect to the choice to confront the professor and for those in the $\mathrm{CSH}$ condition, $p<.001$, rather than the CSH-PV condition. 
Table 4. Logistic Regression Predicting Peer Observers' Intentions for Each Bystander Intervention for Participants in the Three Vignette Conditions

\begin{tabular}{|c|c|c|c|c|c|c|c|}
\hline $\begin{array}{c}\text { Intervention behavior } \\
\text { predictor }\end{array}$ & $\beta$ & $S E$ & Wald $\chi^{2}$ & $d f$ & $\boldsymbol{p}$ & $\operatorname{Exp}(B)$ & $95 \% \mathrm{CI}$ \\
\hline \multicolumn{8}{|c|}{ Interrupt to remove Karen from situation } \\
\hline \multicolumn{8}{|l|}{ Severity } \\
\hline $\mathrm{CSH}$ & -3.74 & .92 & 16.42 & 1 & $<.001$ & .024 & {$[0.004,0.145]$} \\
\hline CSH-PV & -4.50 & 1.26 & 12.68 & 1 & $<.001$ & .01 & {$[0.001,0.132]$} \\
\hline Harm to Karen & -1.02 & .75 & 1.87 & 1 & .171 & .36 & {$[0.083,1.56]$} \\
\hline Personal responsibility & .30 & .90 & .11 & 1 & .739 & 1.35 & {$[0.234,7.77]$} \\
\hline $\begin{array}{l}\text { Consequences of } \\
\text { Intervening }\end{array}$ & .99 & .71 & 1.94 & 1 & .163 & 2.70 & {$[0.669,10.9]$} \\
\hline $\begin{array}{l}\text { Emotions toward } \\
\text { professor }\end{array}$ & -1.31 & .67 & 2.87 & 1 & .090 & .32 & {$[0.087,1.20]$} \\
\hline Emotions toward Karen & -.18 & .83 & .05 & 1 & .825 & .83 & {$[0.163,4.25]$} \\
\hline
\end{tabular}

Confront the professor and tell him to stop

\begin{tabular}{|c|c|c|c|c|c|c|c|}
\hline \multicolumn{8}{|l|}{ Severity } \\
\hline $\mathrm{CSH}$ & -1.30 & .80 & 2.63 & 1 & .015 & .27 & {$[0.057,1.31]$} \\
\hline CSH-PV & -1.38 & .95 & 2.11 & 1 & .146 & .25 & {$[0.039,1.62]$} \\
\hline Harm to Karen & -1.04 & .64 & 6.67 & 1 & .102 & .35 & {$[0.101,1.23]$} \\
\hline Personal responsibility & .36 & .67 & .29 & 1 & .588 & 1.44 & {$[0.388,5 \cdot 31]$} \\
\hline $\begin{array}{l}\text { Consequences of } \\
\text { Intervening }\end{array}$ & 1.99 & .47 & 17.74 & 1 & $<.001$ & $7 \cdot 33$ & {$[2.90,18.52]$} \\
\hline $\begin{array}{l}\text { Emotions toward } \\
\text { professor }\end{array}$ & -1.88 & .55 & 11.60 & 1 & .001 & .15 & {$[0.052, .45]$} \\
\hline Emotions toward Karen & -.11 & .56 & .04 & 1 & .847 & .90 & {$[0.296,2.71]$} \\
\hline \multicolumn{8}{|c|}{ Go find help } \\
\hline \multicolumn{8}{|l|}{ Severity } \\
\hline $\mathrm{CSH}$ & -2.22 & .72 & 9.78 & 1 & .002 & .11 & {$[0.026,0.446]$} \\
\hline CSH-PV & -1.91 & .91 & 4.27 & 1 & .036 & .15 & {$[0.025,0.88]$} \\
\hline Harm to Karen & -.59 & .60 & .95 & 1 & .326 & .55 & {$[0.170,1.80]$} \\
\hline Personal responsibility & -.11 & .66 & .08 & 1 & .867 & .90 & {$[0.247,3.25]$} \\
\hline $\begin{array}{l}\text { Consequences of } \\
\text { Intervening }\end{array}$ & .19 & .46 & .17 & 1 & .649 & 1.21 & {$[0.495,2.94]$} \\
\hline $\begin{array}{l}\text { Emotions toward } \\
\text { professor }\end{array}$ & -1.17 & .51 & 5.27 & 1 & .021 & .31 & {$[0.115,0.84]$} \\
\hline Emotions toward Karen & -.49 & .57 & .68 & 1 & .391 & .62 & {$[2.03,1.87]$} \\
\hline
\end{tabular}

Note. $\mathrm{CSH}$ = coercive sexual harassment; $\mathrm{CSH}-\mathrm{PV}=$ coercive sexual harassment with physical violation. Further information for each analysis for each intervention choice. Interrupt: $-2 \log$ likelihood $=91.29$, Cox - Snell, $R^{2}=.548$, Nagelkerke $R^{2}=.753$, classification $=91.7 \%$. Confront: $-2 \log$ likelihood $=113.41$, Cox - Snell, $R^{2}=.489$, Nagelkerke $R^{2}=$ .672 , classification $=76.1 \%$. Go find help: $-2 \log$ likelihood $=148.56$, Cox-Snell, $R^{2}=.417$, Nagelkerke $R^{2}=.560$; classification $=84.4 \%$. 


\section{Summary and Discussion}

Responding to a social need and gap in the literature (Jacobson \& Eaton, 2017), the current study provides a unique examination of the effects of levels of severity within one form of $\mathrm{SH}$, coercive quid pro quo, upon responses by peer bystanders. Student participants were asked to consider themselves as direct and anonymous witnesses of an interaction between a female student and a male professor. One group read about a professional, nonsexual interaction, while two other groups considered descriptions of coercive quid pro quo $\mathrm{SH}$ that either did (CSH-PV, high severity) or did not (CSH) include forceful physical violation (moderate severity).

Overall, outcomes support the proposition that situational factors (severity of CSH behavior), cognitive appraisals (harm, personal responsibility, probably consequences), and emotional reactions predicted intentions for different types of peer bystander responses to $\mathrm{SH}$ of a female student by a male professor (Bowes-Sperry \& O’Leary-Kelly, 2005; O’Leary-Kelly \& Bowes-Sperry, 2001; Wiener \& Hurt, 2000). There were clear differences between responses of participants in the lowest CSH condition versus those of participants in the two higher CSH conditions. Within the two higher CSH conditions, severity of the harassment affected perceived harm to the student, sense of personal responsibility to act, fear of negative consequences to the self, and intentions to confront the professor during the event. When controlling for other factors, the severity of the harassment was a significant predictor of all three intervention behaviors. Also, negative emotions toward the professor showed significance or a strong trend as a predictor of all three intervention behaviors. Peers' fears of personal consequences seemed to suppress the likelihood of direct confrontation of the professor among those in the CSH condition relative to the high severity, CSH-PV, condition. Thus, it appears that outcomes are compatible with proposals by Bowes-Sperry and O'Leary-Kelly (2005): Direct immediate action is more likely when student bystanders are more certain that what they see actually is something that is more severe, probably closer to what is a normatively agreed-upon offense or emergency, that their response will not make things worse, and/or that they will not suffer personal consequences as a student for acting against the professor on behalf of the peer.

\section{Social Implications}

Results of this study add to our understanding of processes that support bystander interventions against SH in academia. In general, direct confrontation of the professor was the least likely intended response to the immediate situation. Further, findings highlight the challenge of supporting direct helping responses in situations that are more ambiguous and may suggest greater personal risk for direct or indirect witnesses. Our participants generally showed greater fear of personal consequences and of ineffectiveness if they responded unless there was evidence of CSH with forceful physical violation. In the moderate condition, even though there was sexual attention, remarks clarifying quid pro quo benefits, and direct touching by the professor, individuals in that group still reported significantly lower intentions for direct confrontation, higher levels of fear of personal consequences, and even of making the situation worse, if they acted.

These outcomes suggest that institutions are not doing enough to educate the academic community, offer safe options for victims and witnesses, nor enforce the existing laws and legal definitions regarding the full range of CSH behaviors. Institutional shortcomings may be related to the misunderstanding of basic concepts and actual examples of CSH as they are changing and evolving (Page et al., 2016). Confusions and fears to intervene on behalf of a student victim of sexual coercion by a faculty member extend beyond our students to other faculty, staff, and administrative bystanders, putting female students in even more perilous situations (e.g., Crittenden et al., 2018).

Policy clarification, training, and follow-up with enforcement and protection for victims are only part of the picture. Social cognitive components such as beliefs and attitudes that support coercive exploitation, as well as fears about pushing back against harassment, must be addressed. Training must focus on the cognitive 
appraisals and emotional responses of bystanders and consider the moral questions that accompany SH. Evaluation of a moral wrong is different from evaluation of a policy breach, and moral intensity is a strong factor for action to address SH (O’Leary-Kelly \& Bowes-Sperry, 2001). Beyond training in policy, opportunities to rehearse intervention options, where individuals assess cues of SH and how to react on social cognitive and behavioral levels, can enhance sense of personal self-efficacy and action as a bystander helper (Coker et al., 2015; McMahon et al., 2015).

\section{Limitations and Recommendations}

In general, research is still developing in this area of bystander behaviors in response to $\mathrm{SH}$, and in early stages of operationalizing the variables that we wish to study. Vignettes are a common method of manipulating elements of SH behaviors and other situational factors. However, each time researchers focus on a new form of SH or other situational factors, they must create new vignettes that represent the variables of interest. Although it may still be some time to achieve this, it would be helpful for research replication if some standardized versions or criteria for vignettes could be developed over time and employed across studies. For example, we emphasized content validity and explicit legal definitions and descriptions used by colleges and universities to create the specific examples of behaviors for our scenarios; we defined the more severe CSH condition by inclusion of intrusive physical violation, which is compatible with universities' definitions of SH. As a plus, we also included a vignette where friendly, complementary interactions, including the professor's interest in working with the student, were described, but no features specific to CSH were included. Here we wanted to be sure we were tracking contents specific to CSH behaviors as opposed to other types of interpersonal overtures.

On the other hand, our vignettes were longer than would be typical. Because of this, we tried to keep the information immediate by repeating the vignette on each new page of questions. There also is the risk that the initial questions on our survey for the manipulation check may have primed closer thought and evaluation of the vignette's content than if they had not been asked these specific questions (e.g., about the presence of sexual coercion, sexual hostility, etc.). It is unknown how these elements may have affected the outcomes. Following previous research in this area, our dependent measures often were limited to one or two items with Likert-type ordinal scales to operationalize a critical variable. We would welcome more work in this area for further development of relevant, reliable, and valid measures. Finally, this was an online survey. Perhaps completion of this study in environments where peers were present and provided more social cues would influence outcomes.

Ecological validity is challenged when using scenarios, role plays, or videos to create experimental conditions for the study of bystander responses to SH. Research on bystander responses using manipulation of mock, live emergency situations of sexual aggression is limited because of ethical considerations regarding deception without informed consent (Kimmel, 2017). Also, there is questionable reliability and validity of retrospective reports social cognitive and emotional responses by bystanders after they have encountered real-world SH. However, there is theoretical support for assuming that actual bystander responses are at least partially predicted by stated intentions (e.g., Ajzen's, 1991, theory of planned behavior).

Recommendations for future research include examining other factors that may affect readiness to offer direct, immediate aid to the female student victim of faculty CSH, especially in situations where there is uncertainty and fear of consequences. This may include ongoing development and assessment of effectiveness of campus training programs that focus on nuances of $\mathrm{SH}$, rehearsals of various types of bystander helping behaviors, both direct and indirect, and of methods to assure safety for students who act.

Researchers also may examine other situational factors that may affect bystander responses, such as the response of the victim to the perpetrator. Is there less ambiguity if the victim openly confronts the professor for his behavior? Conversely, does an active response by the victim decrease the bystander's appraisal of the 
student's need for help, harm experienced, and so on? On another note, as ethical decision-making is now considered within models of bystander responses to dyadic quid pro quo harassment, it could be informative for future work to incorporate principles from frameworks such as the theory of dyadic morality (Schein, \& Gray, 2018). An improved understanding of these person-level processes can support the development of more person-centered versus policy-centered training of students and other members of the academic community to become bystander activists.

Finally, it is not known if the results observed here are culturally bound, limited to the North American sample of college and university students who were our participants. Perhaps replication of this study with other cultural groups would result in different findings (Cortina \& Wasti, 2005; Zimbroff, 2007).

Unfortunately, we were not able to compare responses in relation to the demographic groups of our participants due to an oversight when setting up the online survey; information from the demographic questionnaire could not be matched to responses on the other survey items once they were assigned to conditions. The time during which the data were collected also may limit the generalization of findings and may have influenced our results. These data were collected in 2018, after the beginning of the \#MeToo movement. There is some indication that in response to the \#MeToo movement, American female college students' attitudes toward SH and harassers have become more negative and punitive than those of their male counterparts (Nodeland \& Craig, 2019). Keplinger et al. (2019) studied differences in reports of workplace harassment in 2016 and 2018, following the beginning of the \#MeToo movement. They found that there were lower rates of reported sexual coercion and unwanted sexual attention in 2018, but gender harassment actually increased. Thus, there seemed to be uneven patterns of attitudes and responses to SH in the time of the \#MeToo movement, depending on gender, type of $\mathrm{SH}$, and other factors that continue to be evaluated.

\section{References}

Ajzen, I. (1991). The theory of planned behavior. Organizational Behavior and Human Decision Processes, 5O(2), 179-211. https://doi.org/1016/o749-5978(91)90020-T

Bandura, A. (1986). Social foundations of thought and action: A social cognitive theory. Prentice-Hall.

Bandura, A. (1989). Human agency in social cognitive theory. The American psychologist, 44(9), 1175-1184. https://doi.org/10.1037/0003-066X.44.9.1175

Barlinska, J., Szuster, A., \& Winiewski, M. (2018). Cyberbullying among adolescent bystanders: Role of affective versus cognitive empathy in increasing prosocial cyberbystander behavior. Frontiers in Psychology, 9. https://doi.org//10.3389/fpsyg.2018.00799

Batson, C. D. (1991). The altruism question: Toward a social-psychological answer. Erlbaum Associates.

Benavides-Espinoza, C., \& Cunningham, G. B. (2010). Bystanders' reactions to sexual harassment. Sex Roles: A Journal of Research, 63(3-4), 201-213. https://doi.org/10.1007/s11199-010-9781-7

Bennett, S., Banyard, V. L., \& Edwards, K. M. (2015). The impact of the bystander's relationship with the victim and the perpetrator on intent to help in situations involving sexual violence. Journal of Interpersonal Violence, 32(5), 682-702. https://doi.org/10.1177/0886260515586373

Bennett, S., Banyard, V. L., \& Garnhart, L. (2014). To act or not to act, that is the question? Barriers and facilitators of bystander intervention. Journal of Interpersonal Violence, 29(3), 476-496. https://doi.org/10.1177/0886260513505210

Bowes-Sperry, L., \& O’Leary-Kelly, A. M. (2005). To act or not to act: The dilemma faced by sexualharassment observers. The Academy of Management Review, 3o(2), 288-306. https://doi.org/10.2307/20159120 
Bowes-Sperry, L., \& Powell, G. N. (1999). Observers' reactions to social-sexual behavior at work: An ethical decision making perspective. Journal of Management, 25(6), 779-802.

https://doi.org/10.1177/014920639902500601

Bursik, K., \& Gefter, J. (2011). Still stable after all these years: Perceptions of sexual harassment in academic contexts. The Journal of Social Psychology, 151(3), 331-349.

https://doi.org/10.1080/00224541003628081

Cameron, C. D., Lindquist, K. A., \& Gray, K. (2015). A constructionist review of morality and emotions: No evidence for specific links between moral content and discrete emotions. Personality and Social Psychology Review, 19(4), 371-394. https://doi.org/10.1177/1088868314566683

Cantalupo, N. C., \& Kidder, W. C. (2018). A systematic look at a serial problem: Sexual harassment of students by university faculty. Utah Law Review, 2018(3), 671-786.

Chui, C. W. S., \& Dietz, J. (2014). Observing workplace incivility toward women: The roles of target reactions, actor motives, and actor-target relationships. Sex Roles: A Journal of Research, 71(1-2), 95-108. https://doi.org/10.1007/s11199-014-0367-7

Chyung, S. Y., Roberts, K., Swanson, I., \& Hankinson, A. (2017). Evidence-based survey design: The use of a midpoint on the Likert scale. Performance Improvement, 56(10), 15-23. https://doi.org/10.1002/pfi.21727

Coker, A. L., Fisher, B. S., Bush, H. M., Swan, S. C., Williams, C. M., Clear, E. R., \& DeGue, S. (2015). Evaluation of the Green Dot bystander intervention to reduce interpersonal violence among college students across three campuses. Violence Against Women, 21(12), 1507-1527. https://doi.org/10.1177/1077801211410264

Cortina, L. M., \& Wasti, S. A. (2005). Profiles in coping: Responses to sexual harassment across persons, organizations, and cultures. Journal of Applied Psychology, 9o(1), 182-192. https://doi.org/10.1037/0021-9010.90.1.182

Crittenden, C. A., Gimlin, A. M., Bennett, A., \& Garland, T. S. (2018). Exploring faculty and students' attitudes about consensual sexual relationships and harassment on college campuses. Educational Policy. Advance online publication. https://doi.org/10.1177/0895904818810522

Davis, M. H. (1996). Empathy: A social-psychological approach. Westview Press.

Diekmann, K., Walker S. D. S., Galinsky, A. D., \& Tenbrunsel, A. E. (2013). Double victimization in the workplace: Why observers condemn passive victims of sexual harassment. Organization Science, 24(2), 614-628. https://doi.org/10.1287/orsc.1120.0753

Equal Employment Opportunity Commission. (n.d.). Facts about sexual harassment. www.eeoc.gov/eeoc/publications/fs-sex.cfm

Fitzgerald, L. F., \& Ormerod, A. J. (1991). Perceptions of sexual harassment: The influence of gender and academic context. Psychology of Women Quarterly, 15(2), 281-294. https://doi.org/10.1111/j.14716402.1991.tboo797.x

Gelfand, M. J., Fitzgerald, L. F., \& Drasgow, F. (1995). The structure of sexual harassment: A confirmatory analysis across cultures and settings. Journal of Vocational Behavior, 47, 164-177. https://doi.org/10.1006/jvbe.1995.1033

Gibbs, J. C. (2019). Moral development and reality: Beyond the theories of Kohlberg, Hoffman, and Haidt. Oxford University Press.

Giner-Sorolla, R., \& Chapman, H. A. (2017). Beyond purity: Moral disgust toward bad character. Psychological Science, 28, 80-91. https://doi.org/10.1177/0956797616673193 
Haidt, J. (2003). The moral emotions. In R. J. Davidson, K. R. Scherer, \& H. H. Goldsmith (Eds.), Handbook of affective sciences (pp. 852-870). Oxford University Press.

Halmburger, A., Baumert, A., \& Schmitt, M. (2015). Anger as a driving factor of moral courage in comparison with guilt and global mood: A multimethod approach. European Journal of Social Psychology, 45, 39-51. https://doi.org/10.1002/ejsp.2071

Hellemans, C., Dal Cason, D., \& Casini, A. (2017). Bystander helping behavior in response to workplace bullying. Swiss Journal of Psychology, 76(4), 135-144. https://doi.org/10.1024/1421-0185/a0o0200

Jacobson, R. K., \& Eaton, A. A. (2018). How organizational policies influence bystander likelihood of reporting moderate and severe sexual harassment at work. Employee Responsibilities and Rights Journal, 30, 37-62. https://doi.org/10.10007/s10672-017-9309-1

Jones, T. M. (1991). Ethical decision making by individuals in organizations: An issue-contingent model. Academy of Management Review, 16, 366-395. https://doi.org/10.2307/258867

Keplinger, K., Johnson, S. K., Kirk, J. F., \& Barnes, L. Y. (2019). Women at work: Changes in sexual harassment between September 2016 and September 2018. PLOS ONE, 14(7), . e0218313 https://doi.org/10.1371/journal.pone.0218313

Kimmel, A. J. (2017). Ethical issues in social influence research. In S. G. Harkins, K. D. Williams, \& J. M. Burger (Eds.), The Oxford handbook of social influence (pp. 11-32). Oxford University Press. https://doi.org/ 10.1093/oxfordhb/9780199859870.013.2

Laird, A. A., \& Pronin, E. (2019). Professors' romantic advances undermine students' academic interest, confidence, and identification. Sex Roles, 81, 1-15. https://doi.org/10.1007/s11199-019-01093-1

Latané, B., \& Darley, J. M. (1970). The unresponsive bystander: Why doesn't he help? Prentice Hall.

Latané, B., \& Nida, S. (1981). Ten years of research on group size and helping. Psychological Bulletin, 89, 308-324. https://doi.org/10.1037//o033-2909.89.2.308

McMahon, S., Peterson, N. A., Winter, S. C., Palmer, J. E., Postmus, J. L., \& Koenick, R. A. (2015). Predicting bystander behavior to prevent sexual assault on college campuses: The role of self-efficacy and intent. American Journal of Community Psychology, 56(102), 46-56. https://doi.org/10.1007/s10464-0159740-0

Moylan, C. A., \& Wood, L. (2016). Sexual harassment in social work field placements: Prevalence and characteristics. Affilia, 31(4), 405-417. https://doi.org/10.1177/0886109916644643

National Academies of Sciences, Engineering, and Medicine. (2018). Sexual harassment of women: Climate, culture, and consequences in academic sciences, engineering, and medicine. The National Academies Press. https://doi.org/10.17226/24994

Nickerson, A. B., Aloe, A. M., Livingston, J. A., \& Feeley, T. H. (2014). Measurement of the bystander intervention model for bullying and sexual harassment. Journal of Adolescence, 37, 391-400. https://doi.org/10.1016/j.adolescence.2014.03.003

Nodeland, B., \& Craig, J. (2019, Nov.). Perceptions of legal and extralegal punishments for sexual harassment in the "MeToo" era. Deviant Behavior. Advance online publication. https://doi.org/10.1080/01639625.2019.1702615

Northwestern University. (2018). Comprehensive policy on sexual misconduct . https://www.northwestern.edu/sexual-misconduct/docs/sexual_misconduct_policy.pdf

O'Leary-Kelly, A. M., \& Bowes-Sperry, L. (2001). Sexual harassment as unethical behavior: The role of moral intensity. Human Resource Management Review, 11(1-2), 73-92. https://doi.org/10.1016/S10534822(00)00041-3 
Page, T., Pina, A., \& Giner-Sorolla, R. (2016). “It was only harmless banter!” The development and preliminary validation of the moral disengagement in SH scale. Aggressive Behavior, 42, 254-273. https://doi.org/10.1002/ab.21621

Peer, E., Brandimarte, L., Samat, S., \& Acquisti, A. (2017). Beyond the Turk: Alternative platforms for crowdsourcing behavioral research. Journal of Experimental Social Psychology, 70, 153-163. https://doi.org/10.1016/j.jesp.2017.01.006

Rest, J. R. (1986). Moral development: Advances in research and theory. New York, NY: Praeger.

Rosenthal, M. N., Smidt, A. M., \& Freyd, J. J. (2016). Still second class: Sexual harassment of graduate students. Psychology of Women Quarterly, 40(3), 364-377. https://doi.org/10.1177/0361684316657822

Schein, C., \& Gray, K. (2018). The theory of dyadic morality: Reinventing moral judgment by redefining harm. Personality and Social Psychology Review, 22(1), 32-70. https://doi.org/10.1177/1088868317698288

Swarthmore College. (2019). What is sexual assault? https://www.swarthmore.edu/share/what-sexualassault

Tata, J. (2000). She said, he said: The influence of remedial accounts on third-party judgments of coworker sexual harassment. Journal of Management, 26(6), 1133-1156. https://doi.org/10.1177/014920630002600604

Tenbrunsel, A. E., Rees, M. R., \& Diekmann, K. A. (2019). Sexual harassment in academia: Ethical climates and bounded ethicality. Annual Review of Psychology, 70, 245-270. https://doi.org/10.1146/annurev-psych-010418-102945

Terpstra, D. E., \& Baker, D. D. (1987). A hierarchy of sexual harassment. The Journal of Psychology: Interdisciplinary and Applied, 121(6), 599-605. https://doi.org/10.1080/00223980.1987.9712689

The State University of New York. (2018). Sexual harassment response and prevention statement. https://www.suny.edu/sunypp/documents.cfm?doc_id=878

Weiss, D. S., \& Lalonde, R. N. (2001). Responses of female undergraduates to scenarios of sexual harassment by male professors and teaching assistants. Canadian Journal of Behavioural Science/Revue canadienne des sciences du comportement, 33(3), 148. https://doi.org/10.1037/hoo87137

Wiener, R. L., \& Hurt, L. E. (2000). How do people evaluate social sexual conduct at work? A psycholegal model. Journal of Applied Psychology, 85, 75-85. https://doi.org/10.1037//o021-9010.85.1.75

Worth v. Tyler, 2001276 F.3d 249, 7th Cir. (2001). https://casetext.com/case/worth-v-tyer-2

Zimbroff, J. (2007). Cultural differences in perceptions of and responses to sexual harassment. Duke Journal of Gender, Law, \& Policy, 14, 1311-1341. https://scholarship.law.duke.edu/cgi/viewcontent.cgi?article=1140\&context=djglp

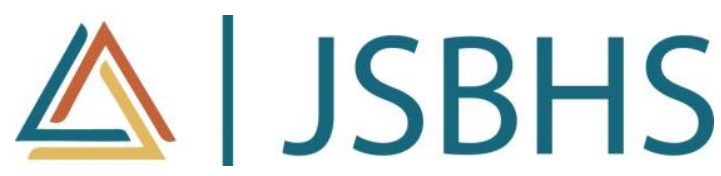

The Journal of Social, Behavioral, and Health Sciences (JSBHS), co-sponsored by the College of Health Sciences and the College of Social and Behavioral Sciences at Walden University, is a peer-reviewed, online, interdisciplinary journal focusing on theoretically-based research that addresses contemporary national and international issues. $J S B H S$ articles include peer-reviewed research reports, brief resports, comprehensive literature reviews, books reviews, and student research. 